\title{
Electrochemistry of Caffeic Acid in
}

\section{Acetate-Ethanolic Solutions}

\author{
S.C. Mordido, ${ }^{a}$ M.J.F. Rebelo, ${ }^{a, b, *}$ \\ ${ }^{a}$ Departamento de Química e Bioquímica, Faculdade de Ciências da Universidade de Lisboa \\ (FCUL), ${ }^{b}$ CECUL -FCUL, Campo Grande, C 8, 1749-016 Lisboa, Portugal
}

Received 30 November 2005; accepted in revised form 2 March 2006

\begin{abstract}
The electrochemical behaviour of caffeic acid in acetate solutions with and without added ethanol was studied by cyclic voltammetry. Solutions of $\mathrm{pH}$ and ethanol content close to the wine values ( 3.5 and $12 \%$, respectively) were studied as a first model approach, pursuing work previously done. Studies at $\mathrm{pH} 7.4$ and different ionic strengths were also done.

It was found that cyclic voltammograms of caffeic acid acetate ethanolic solutions had oxidation peak potential values $(\approx 470 \mathrm{mV})$ at $\mathrm{pH} 3.5$ irrespective of the previous excursions of potential with the same set of electrodes. However, the cathodic peaks potentials and currents strongly depended on the cyclic voltammogram of the corresponding solvent electrolyte which had previously been run.

The separation of oxidation and reduction peak potentials evidenced the presence of dimmers of caffeic acid in solution, under the following conditions: $0.1 \mathrm{~mol} \mathrm{dm}^{-3}$ acetate buffer $\mathrm{pH} 3.5+12 \%$ ethanol with the ionic strength increased by the addition of $0.05 \mathrm{~mol} \mathrm{dm}{ }^{-3} \mathrm{KCl}$; limits of the anodic potential: from -100 to $+700 \mathrm{mV}$ and $\mathrm{N}_{2}$ bubbled through the solution for 10 minutes.
\end{abstract}

Keywords: caffeic acid, acetate buffer, ethanol, cyclic voltammetry.

\section{Introduction}

Caffeic acid (CA) is a polyphenol (compound containing aromatic ring and hydroxyl groups). It is 3,4-dihydroxycinnamic acid, $\mathrm{C}_{9} \mathrm{H}_{8} \mathrm{O}_{4}$ and is found in fruits, vegetables, wine, olive oil, tea and coffee beans. It has antioxidant properties and, thus, potential prevention of cardiovascular disease, atherosclerosis, cancer, inflammation, and cataracts. Physiological systems might

\footnotetext{
* Corresponding author. E-mail address: mjrebelo@fc.ul.pt
} 
suffer oxidative stress caused by excessive exposure to oxidants and or a decrease in the antioxidant capacity of the system. As a consequence, reactive oxygen species (ROS) are formed. Low-molecular weight antioxidants are small molecules that react with ROS. They can be endogenous such as glutathione (GSH), nicotinamide adenine dinucleotide (NADH), uric acid (UA) and bilirubin, or obtained from the diet such as ascorbic acid (AA), tocopherols and polyphenols [1].

In vitro studies found that $\mathrm{CA}$ inhibited human low-density lipoprotein oxidation induced by different systems $\left[\mathrm{Cu}^{2+}, 2,2^{\prime}\right.$-azobis(2-amidinopropane) (AAPH) macrophages] by both a transient chelation of the copper catalyst and the scavenging of reactive oxygen species and free radicals [2, 3, 4]. Moreover, CA exhibited a sparing effect toward alpha-tocopherol and beta-carotene [2]. The ability of caffeic acid to reduce glutathione depletion and to inhibit lipid peroxidation during t-butyl hydroperoxide induced oxidative stress has also been claimed [5]. Despite its inhibition of $\mathrm{Ca}^{2+}$ induced LDL oxidation in the initiation phase it acts as a prooxidant in the propagation phase. It has also been claimed to be a non-competitive inhibitor of xanthine oxidase.

The enzymatic oxidation of o-diphenols to the corresponding very reactive oquinones is the first step in browning of fruits. O-quinones can react in several ways. They can act as electrophiles, thus, as oxidants for other substances with lower reduction potentials and they might condense with the corresponding hydroquinones - if there are not other substrates present. [6] The enzymatic oxidation of CA in the presence of laccase has been used in the construction of caffeic acid biosensors [7] and its application for determinations in red wine has been done [8].

Studies of the oxidation of caffeic acid have been done in aqueous solutions with $\mathrm{pH} 2.0$ to $8.5[9,10]$, in acetonitrile [11] and in $1: 1(\mathrm{v} / \mathrm{v})$ water-ethanol phosphate buffer $\mathrm{pH} 7.0$ [12]. A voltammogram of the oxidation of a $10^{-3} \mathrm{~mol} \mathrm{~L}^{-1}$ caffeic acid solution at $\mathrm{pH} \quad 4$ and a scan rate of $0.2 \mathrm{~V} \mathrm{~s}^{-1}$ has also been reported [11]. However, the electrochemical behaviour of hydro-ethanolic solutions of this relevant polyphenol is not completely understood. Our interest in the application of the caffeic biosensor in red wine led us to study its electrochemical redox behaviour in solutions containing $12 \%(\mathrm{v} / \mathrm{v})$ ethanol and $\mathrm{pH} 3.5$.

\section{Experimental \\ Materials}

trans - 3,4- dihydroxycinnamic acid (caffeic acid) was from Aldrich. Absolut ethanol, density $1.790 \mathrm{~kg} / \mathrm{L}$, was from Panreac Quimica AS. Buffers used were: PBS (phosphate buffer saline) $\mathrm{pH}=7.4$, prepared with $\mathrm{NaCl}$ from Riedel-deHaën with purity greater than $99.8 \%, \mathrm{KCl}$ from Merck, purity superior to $99.5 \%$, $\mathrm{Na}_{2} \mathrm{HPO}_{4}$ and $\mathrm{KH}_{2} \mathrm{PO}_{4}$, with purity superior to $99.9 \%$ and $99.7 \%$, respectively, both supplied by Sigma-Aldrich. Acetate buffer was prepared with sodium acetate trihydrated, from Sigma, having purity superior to $99.8 \%$, and glacial acetic acid from Riedel-de-Haën, with purity of $99.8 \%$ and density $1.05 \mathrm{~kg} / \mathrm{L}$. Bidistilled Millipore water was used to make up the solutions. 
Caffeic acid solutions were freshly prepared the day of the experiment.

\section{Cyclic voltammetry}

Cyclic voltammograms (CV) of the buffers and the caffeic acid solutions were obtained with a Voltalab 10, PGZ100 from Radiometer Analytical, coupled to a personal computer. A two compartment cell having a Luggin capillary and three electrodes was used. The working electrode was a platinum disc with $5 \mathrm{~mm}$ diameter, the auxiliary electrode was a platinum plate having an area $\approx 1 \mathrm{~cm}^{2}$ and the reference one was a saturated calomel electrode (SCE) from Radiometer Analytical. The working electrode was polished to a mirror finish with $0.05 \mu \mathrm{m}$ alumina paste and thoroughly rinsed with Millipore water and the corresponding solution to be studied prior to each set of voltammetric measurements. The auxiliary electrode was washed with concentrated nitric acid, thoroughly rinsed with Millipore water before each experiment. SCE was stored in saturated $\mathrm{KCl}$ while not in use. Nitrogen was bubbled through some of the solutions for 10 minutes. The voltammograms were run at room temperature (ca. $25^{\circ} \mathrm{C}$ ).

\section{Results}

\section{Influence of previous scans on the oxidation of caffeic acid}

It is common practice to run voltammograms of the background electrolyte before doing it for the analyte solution with the aim of distinguishing between the features of the test analyte and the ones from the background solvent/supporting electrolyte $[9,10,13]$. Accordingly we have run cyclic voltammograms of $10^{-3}$ mol dm${ }^{-3}$ caffeic acid solution in $0.1 \mathrm{~mol} \mathrm{dm}^{-3}$ acetate buffer $\mathrm{pH} 3.5+12 \%$ ethanol after having done CV's for a) $0.1 \mathrm{~mol} \mathrm{dm}^{-3}$ acetate buffer $\mathrm{pH} 3.5$ and, b) $0.1 \mathrm{~mol} \mathrm{dm}^{-3}$ acetate buffer $\mathrm{pH} 3.5+12 \%$ ethanol, all at $100 \mathrm{mV} / \mathrm{s}$. It was observed that the same stock solution of caffeic acid would yield an oxidation peak at $\approx 500 \mathrm{mV}$ which was observed whatever voltammogram was previously run. However, after that first peak different voltammograms were obtained, depending on the previous background electrolytes that were used with the same cell and electrodes. It must be stressed again that the working and the auxiliary electrodes were prepared before each experiment in the way it was described at the experimental section. Thus, it was observed - Fig. 1 - that the first oxidation peak at $\approx 500 \mathrm{mV}$ vs. SCE, due to the oxidation of the ortho hydroxyl groups of caffeic acid $[9,14]$, could be seen at both voltammograms. For potentials larger than the one of that peak, the increase of the current was due to the oxidation of ethanol. As a matter of fact the previously run $\mathrm{CV}$ on $0.1 \mathrm{~mol} \mathrm{dm}^{-3}$ acetate buffer $\mathrm{pH} 3.5+12 \%$ ethanol evidenced that fact, as seen in Fig. 2 . 


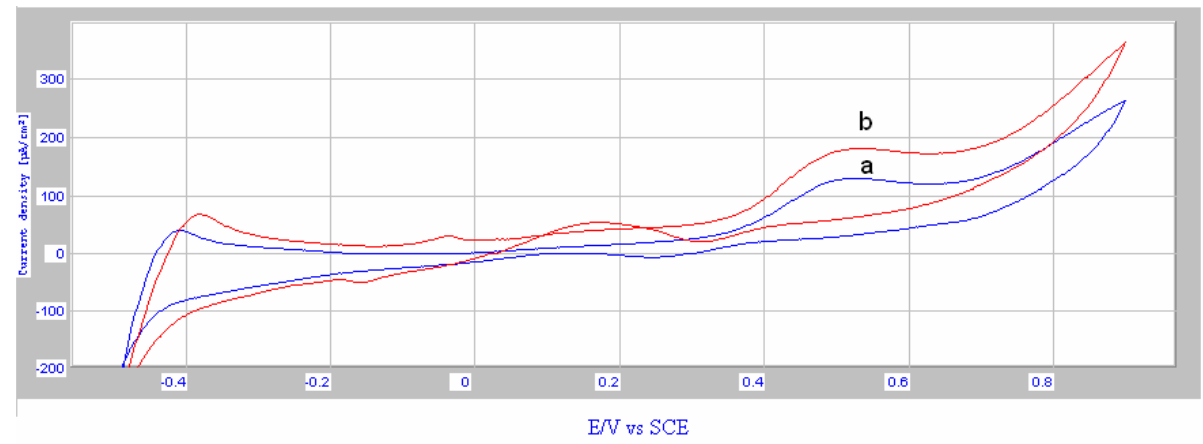

Figure 1. CV of $1.0 \times 10^{-3} \mathrm{~mol} \mathrm{dm}^{-3}$ caffeic acid in $0.1 \mathrm{~mol} \mathrm{dm}^{-3}$ acetate buffer $\mathrm{pH}$ $3.5+12 \%$ ethanol, at $100 \mathrm{mV} / \mathrm{s}$, as a function of previous scans: $\mathbf{a} \rightarrow$ after having scanned the potential in acetate buffer only; $\mathbf{b} \rightarrow$ after having scanned the potential in acetate buffer $+12 \%$ ethanol.

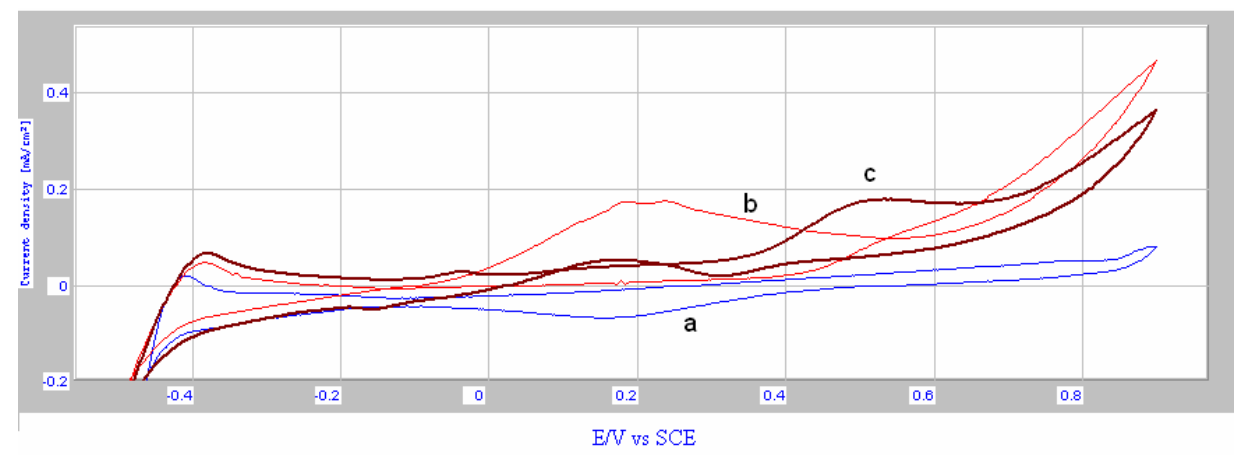

Figure 2. $\mathrm{CV}$ of $1.0 \times 10^{-3} \mathrm{~mol} \mathrm{dm}^{-3}$ caffeic acid in $0.1 \mathrm{~mol} \mathrm{dm}^{-3}$ acetate buffer $\mathrm{pH}$ $3.5+12 \%$ ethanol vs. CV's of supporting electrolyte: $\mathbf{a} \rightarrow 0.1 \mathrm{~mol} \mathrm{dm}^{-3}$ acetate buffer $\mathrm{pH} 3.5 ; \mathbf{b} \rightarrow 0.1 \mathrm{~mol} \mathrm{dm}^{-3}$ acetate buffer $\mathrm{pH} 3.5+12 \%$ ethanol; $\mathbf{c} \rightarrow 1.0 \times 10^{-3} \mathrm{~mol} \mathrm{dm}^{-3}$ caffeic acid in $0.1 \mathrm{~mol} \mathrm{dm}^{-3}$ acetate buffer $\mathrm{pH} 3.5+12 \%$ ethanol, all at $100 \mathrm{mV} / \mathrm{s}$.

That increase was less pronounced in the caffeic acid solution than in the $0.1 \mathrm{~mol}$ $\mathrm{dm}^{-3}$ acetate buffer $\mathrm{pH} 3.5+12 \%$ ethanol. At those potentials the electrochemical oxidation of ethanol occurs [15] and the presence of caffeic acid competes for the same platinum sites, decreasing the ethanol oxidation [16]. Only a slight reduction peak was observed in the region around $300 \mathrm{mV}$ in the cathodic scan. The corresponding cathodic peak current is smaller than the anodic peak current assigned to caffeic acid oxidation. That is an indication of chemical reactions of the products of caffeic acid oxidation. The main difference observed in the cathodic scan of the caffeic acid solution was the appearance of an oxidation wave around $200 \mathrm{mV}$, which was probably due to a reoxidation of ethanol [16] when the $\mathrm{CV}$ was run after the one run in ethanol containing acetate buffer.

That reoxidation was not observed at the corresponding cathodic scan after having done a previous voltammogram in acetate buffer only. 
Influence of the scan rate, the limiting value of the anodic potential and the ionic strength

Varying the scan rate of $1.0 \times 10^{-3} \mathrm{~mol} \mathrm{dm}^{-3}$ caffeic acid in $0.1 \mathrm{~mol} \mathrm{dm}^{-3}$ acetate buffer $\mathrm{pH} 3.5+12 \%$ ethanol, from 10 to $100 \mathrm{mV} / \mathrm{s}$, the voltammograms shown on Fig. 3 were obtained:

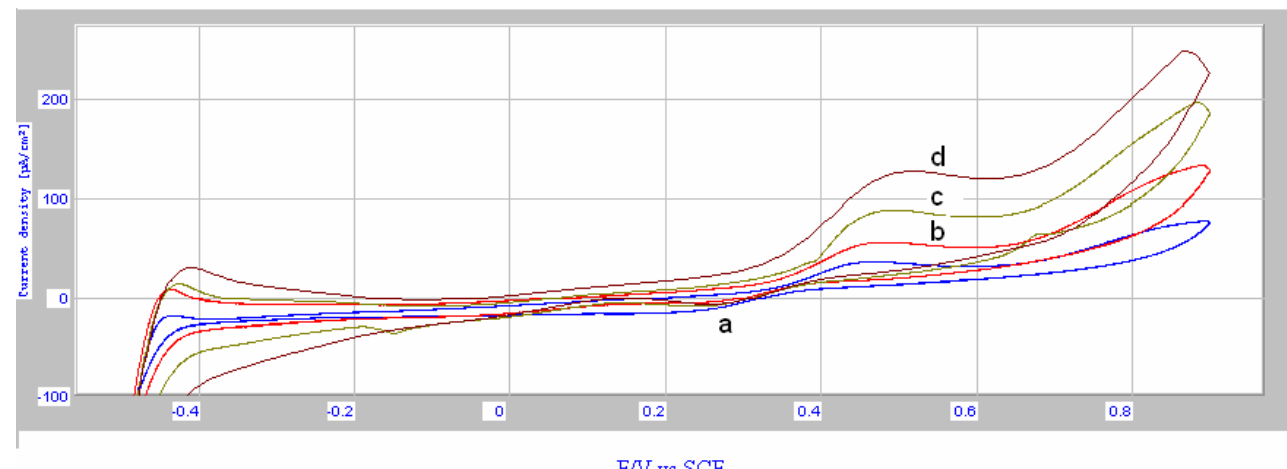

Figure 3. $\mathrm{CV}$ of $1.0 \times 10^{-3} \mathrm{~mol} \mathrm{dm}^{-3}$ caffeic acid in $0.1 \mathrm{~mol} \mathrm{dm}^{-3}$ acetate buffer $\mathrm{pH}$ $3.5+12 \%$ ethanol $v s$. scan rate $(\mathrm{mV} / \mathrm{s}): \mathbf{a} \rightarrow 10, \mathbf{b} \rightarrow 20, \mathbf{c} \rightarrow 50$ and $\mathbf{d} \rightarrow 100(\mathrm{mV} / \mathrm{s})$.

It was observed that the anodic peak current for the oxidation of caffeic acid was proportional to the square root of the scan which means that it is diffusion controlled. The oxidation peak potentials were slightly displaced to more positive potentials as the scan rate increased (Table 1).

Table 1. Oxidation peak potentials of $1.0 \times 10^{-3} \mathrm{~mol} \mathrm{dm}^{-3}$ caffeic acid in $0.1 \mathrm{~mol} \mathrm{dm}^{-3}$ acetate buffer $\mathrm{pH} 3.5+12 \%$ ethanol, as a function of the scan rate.

\begin{tabular}{cc}
\hline Scan rate $/ \mathrm{mVs}^{-1}$ & $\mathrm{E}_{\mathrm{pa} / \mathrm{mV}}$ \\
\hline 10 & 459.7 \\
20 & 472.6 \\
50 & 478.6 \\
100 & 507.0 \\
\hline
\end{tabular}

The reoxidation of ethanol increased from 20 to $100 \mathrm{mV} / \mathrm{s}$.

In order to focus on the first oxidation peak due to caffeic acid, we have changed the limits of the anodic potential (from -100 to $+700 \mathrm{mV}$ ), increased the ionic strength either by the addition of $0.05 \mathrm{~mol} \mathrm{dm}^{-3} \mathrm{KCl}$ [12] or by increasing the concentration of the acetate buffer to $0.2 \mathrm{~mol} \mathrm{dm}^{-3}$ [17] and bubbled $\mathrm{N}_{2}$ through the solution for 10 minutes. The voltammograms thus obtained were those of Fig. 4. 


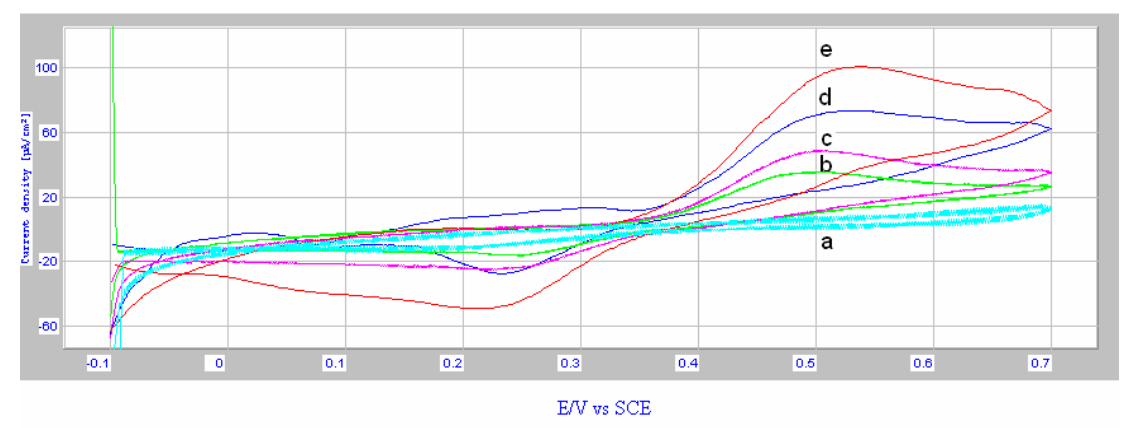

Figure 4. CV's of $1.0 \times 10^{-3} \mathrm{~mol} \mathrm{dm}^{-3}$ caffeic acid in $0.1 \mathrm{~mol} \mathrm{dm}^{-3}$ acetate buffer $\mathrm{pH}$ $3.5+12 \%$ ethanol with added $0.05 \mathrm{~mol} \mathrm{dm}^{-3} \mathrm{KCl}$ at scan rates 10 to $100 \mathrm{mV} / \mathrm{s}\left(\mathrm{N}_{2}\right.$ bubbled for 10 minutes): $\mathbf{b} \rightarrow 10, \mathbf{c} \rightarrow 20, \mathbf{d} \rightarrow 50$ and $\mathbf{e} \rightarrow 100(\mathrm{mV} / \mathrm{s}) .\left(\mathrm{N}_{2}\right.$ bubbled for $10 \mathrm{~min}$ ) [a: Acetate buffer, $20 \mathrm{mV} / \mathrm{s}$ ].

It was observed that here was an oxidation peak at a potential close to what had been observed under slightly different conditions and a new cathodic peak appeared. The difference between the oxidation and the reduction peak potentials was $(\mathrm{Epa}-\mathrm{Epc}) / 60 \approx 4$. This result added evidence to the formation of dimers of caffeic acid having four oxidizable hydroxyls [12] as shown on scheme 1.

The formation of these tetrahydrofuran derivatives has been observed at $\mathrm{pH} 3.6$ [6]. At $\mathrm{pH}$ larger than 4.6 they were not observed.

Similar voltammograms were obtained when $0.2 \mathrm{~mol} \mathrm{dm}^{-3}$ acetate buffer was used as supporting electrolyte at 10 and $20 \mathrm{mV} / \mathrm{s}$ scan rates. However unpredictable results were obtained when the scan rates were 50 and $100 \mathrm{mV} / \mathrm{s}$. An influence of the increase of the buffer concentration on caffeic acid oxidation was also observed by other authors [6].

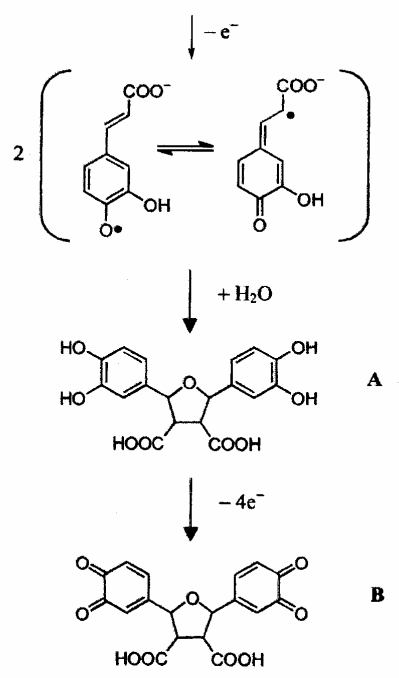

Scheme 1. Formation of dimmers of caffeic acid and corresponding oxidation. 


\section{The pH influence}

The influence of the $\mathrm{pH}$ was studied varying the buffer electrolyte to PBS (phosphate buffer saline, that is $\mathrm{Na}_{2} \mathrm{HPO}_{4}, \mathrm{KH}_{2} \mathrm{PO}_{4}, \mathrm{KCl}$ and $\mathrm{NaCl}$ at concentrations: $0.008,0.0018,0.0033,0.17 \mathrm{~mol} \mathrm{dm}^{-3}$ ) $\mathrm{pH}$ 7.4. Comparison of the influence of these two $\mathrm{pH}$ values is shown on Fig. 5.

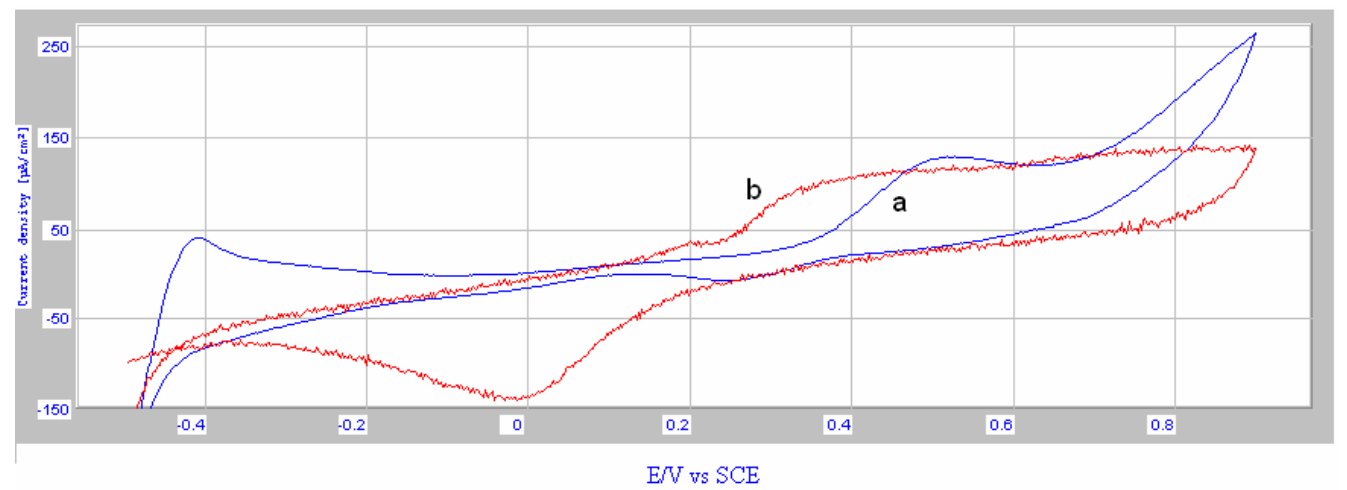

Figure 5. CV's of $1.0 \times 10^{-3} \mathrm{~mol} \mathrm{dm}^{-3}$ caffeic acid: in $0.1 \mathrm{~mol} \mathrm{dm}^{-3}$ acetate buffer $\mathrm{pH}$ $3.5+12 \%$ ethanol (a); and in PBS pH 7.4 (b), at $100 \mathrm{mV} / \mathrm{s}$.

The oxidation peak potential is more negative when the $\mathrm{pH}$ is 7.4 than 3.5 , that is the antioxidant activity is thermodynamically favored with the increase in $\mathrm{pH}$ $[10,18]$. That behaviour is typical of oxidations which are accompanied by the participation of protons.

\section{Effect of the scan rate on the CV's of caffeic acid in PBS}

It was observed that the oxidation of caffeic acid occurred at potentials which had values close to the one reported by Born et al. [19], $\mathrm{E}_{\mathrm{pa}}=0.23 \mathrm{~V}$, under the same $\mathrm{pH} 7.4$, but slightly different conditions (they used $0.07 \mathrm{M}$ phosphate buffer $/ \mathrm{EtOH} \mathrm{1:1} \mathrm{(v/v)} \mathrm{working} \mathrm{electrode} \mathrm{GC}$ vs. $\mathrm{Ag} / \mathrm{AgCl} 3 \mathrm{M} \mathrm{KCl})$. The reduction peak potential was also at a value close to that one observed by Born et al., $\mathrm{E}_{\mathrm{pc}}=$ $0.02 \mathrm{~V}$, although our results point to a mixed reduction potential. In fact, at $\approx$ $-100 \mathrm{mV}$ it was observed by us only when PBS was present, as seen on Fig. 6 .

Repetitive cycling of the potential in the caffeic acid solution under study resulted in an increase of the anodic peak current from the $1^{\text {st }}$ to the $5^{\text {th }}$ cycle when the previous scans had been run in acetate buffer only (cf. Fig. 7A). On the contrary, a decrease of the anodic peak current was observed when going from the $1^{\text {st }}$ to the $5^{\text {th }}$ cycle after the electrodes had been previously subjected to scans in ethanol containing acetate buffer (Fig. 7B).

The above referred increase in current upon successive scans points to the formation of an electroactive film onto the working electrode surface. The decrease of the anodic current observed under the other conditions, that is, after having run previous scans in ethanolic containing buffer, is most probably due to the prevailing effect of the products of ethanol oxidation which will certainly form upon cycling the potential in ethanolic containing solutions. 


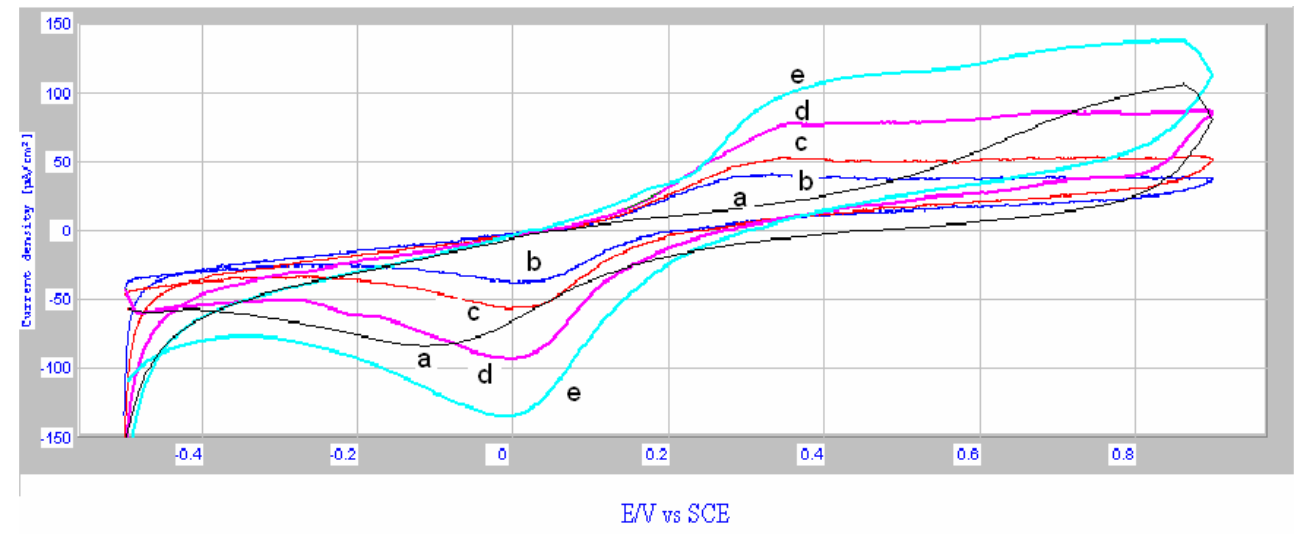

Figure 6. $\mathrm{Cv}$ of $1.0 \times 10^{-3} \mathrm{~mol} \mathrm{dm}^{-3}$ caffeic acid in PBS vs. scan rate: $\mathbf{b} \rightarrow 10, \mathbf{c} \rightarrow 20$, $\mathbf{d} \rightarrow 50$ and $\mathbf{e} \rightarrow 100(\mathrm{mV} / \mathrm{s})$. a: PBS $100 \mathrm{mV} / \mathrm{s}$.

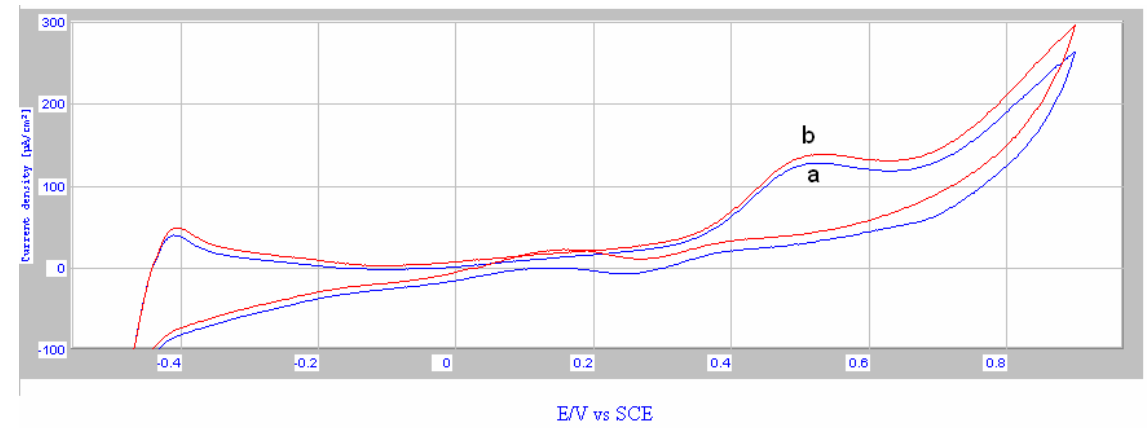

Fig. 7 A. $1.0 \times 10^{-3} \mathrm{~mol} \mathrm{dm}^{-3}$ caffeic acid in $0.1 \mathrm{~mol} \mathrm{dm}^{-3}$ acetate buffer $\mathrm{pH} 3.5+12 \%$ ethanol, at $100 \mathrm{mV} / \mathrm{s}$ after having scanned the potential in acetate buffer: a: $1^{\text {st }}$ cycle; b: $5^{\text {th }}$ cycle.

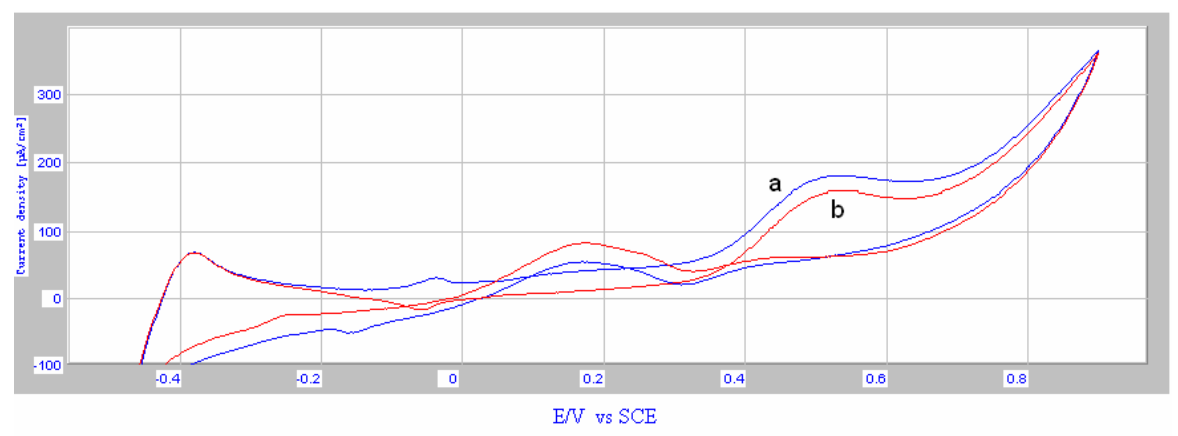

Figure 7 B. $1.0 \times 10^{-3} \mathrm{~mol} \mathrm{dm}^{-3}$ caffeic acid in $0.1 \mathrm{~mol} \mathrm{dm}^{-3}$ acetate buffer $\mathrm{pH} 3.5+12 \%$ ethanol, at $100 \mathrm{mV} / \mathrm{s}$ after having scanned the potential in acetate buffer $+12 \%$ ethanol: $\mathbf{a} \rightarrow 1^{\text {st }}$ cycle; $\mathbf{b} \rightarrow 5^{\text {th }}$ cycle. 


\section{Conclusions}

The oxidation of caffeic acid was observed in several different conditions. In fact, the oxidation peak at values in the range 450 to $500 \mathrm{mV}$ vs. SCE was observed in solutions of $\mathrm{pH} 3.5$ in acetate buffer solution with and without $12 \%$ ethanol, either being air

saturated or bubbled with $\mathrm{N}_{2}$. The oxidation peak appeared at lower potential values in PBS solution, $\mathrm{pH} 7.4\left(\mathrm{E}_{\mathrm{pa}} \approx 300 \mathrm{mV}\right)$. Oxidation waves observed at potentials larger than $600 \mathrm{mV}$ were observed in ethanol containing solutions. At those potentials, however, ethanol also oxidizes and assignment of anodic currents to caffeic acid could not be done. So, the presence of ethanol did not interfere at the peak potential characteristic of the oxidation of the ortho hydroxyl groups but masked any other processes which might be occurring at higher potentials. The cathodic scan had a variety of shapes depending on the limit of the anodic potential and the ionic strength. When the potential scan was taken up to values larger than $700 \mathrm{mV}$, say $900 \mathrm{mV}$, a cathodic peak could be observed at potential close to $300 \mathrm{mV}$. Reoxidation peaks of ethanol were also observed. Reduction peak potentials were obtained in caffeic acid solutions, at potentials such that $(\mathrm{Epa}-\mathrm{Epc}) / 60 \approx 4$, when the limit of the oxidation peak potential was $700 \mathrm{mV}$, and the ionic strength was high (ca. 0.2). This latter observation evidenced the existence of dimmers of caffeic acid in the solution as well as their redox behaviour.

\section{References}

1. S. Chevion, M.A. Roberts, and M. Chevion, Free Rad. Biol. Med. 28(6) (2000) 860-870.

2. M. Nardini, M. D’Aquino, G. Tomassi, V. Gentili, M. Di Felice, C. Scaccini, Free Radic. Biol. Med. 19 (1995) 541-552.

3. J. Laranjinha, O. Vieira, V. Madeira, L. Almeida, Arch. Biochem. Biophys. 323 (1995) 373-381.

4. D. Galato, K. Ckless, M.F. Susin, C. Giacomelli, R.M. Ribeiro-do-Valle, and A. Spinelli, Redox Rep. 6 (2001) 243-250.

5. M. Nardini, P. Pisu, V. Gentili, F. Natella, M. Di Felice, E. Piccolella, and C. Scaccini, Free Radic. Biol. Med. 25 (9) (1998) 1098-1105.

6. H. Fulcrand, A. Cheminat, R. Brouillard, V. Cheynier, Phytochemistry 35 (1994) 499-505.

7. S.A.S.S. Gomes and M.J.F. Rebelo, Sensors 3 (2003) 166-175.

8. S.A.S.S. Gomes, J.M.F. Nogueira, M.J.F. Rebelo, Biosens. Bioelectr. 20 (6) (2004) 1211-1216.

9. C. Giacomelli, K. Ckless, D. Galato, F.S. Miranda, A. Spinelli, J. Braz. Chem. Soc. 13(3) (2002) 332-338.

10. J.M.D. Markovic', L.M. Ignjatovic', D. Markovic', J.M. Baranac, J. Electroanal. Chem. 553 (2003) 169-175.

11. P. Hapiot, A. Neudeck, J. Pinson, H. Fulcrand, P. Neta, C. Rolando, J. Electroanal. Chem. 405 (1996) 169-176.

12. H. Hotta, S. Nagano, M. Ueda, Y. Tsujino, J. Koyama, T. Osakai, Biochim. Bioph. Acta 1572 (2002) 123-132. 
13. M.-E. Ghica, A.M.O. Brett, Electroanalysis 17(4) (2005) 313-318.

14. P.A. Kilmartin, H. Zou, A.L. Waterhouse, J. Agric. Food Chem. 49 (2001) 1957-1965.

15. C. Lamy, E.M. Belgsir, J.M. Léger, J. Appl. Electrochem. 31 (2001) 799809.

16. S. Andreescu, D. Andreescu, O.A. Sadik, Electrochem. Comm. 5 (2003) 681-688.

17. P. Janeiro, A.M.O. Brett, Anal. Chim. Acta 518 (2004) 109 - 115.

18. C. Giacomelli, F.C. Giacomelli, L.O. Alves, A.K. Timbola, A. Spinelli, J. Braz. Chem. Soc. 15(5) (2004) 748-755.

19. M. Born, P.-A. Carrupt, R. Zini, F. Brée, J.-P. Tillement, K. Hostettmann, B. Testa, Helv. Chim. Acta 79 (1996) 1147-1158. 